\title{
GROWTH ACCOUNTING, TOTAL FACTOR PRODUCTIVITY AND APPROXIMATION PROBLEM
}

\author{
Jan Čadi**
}

\begin{abstract}
Abtract:
The paper deals with the approximation problem of standard growth accounting method first introduced by Solow (1957). This method is still used widely by lots of economists and institutions (IMF, national banks and others) for computing the technological or total factor productivity (TFP) dynamics. According to standard growth accounting the TFP growth is a residual, computed simply out of dynamic Cobb-Douglas (original or modified) production function.

The purpose of this paper is to show that the usual TFP calculation as a residual is more or less inaccurate and for certain cases can cause slightly biased conclusions. The idea of such weak approximation is based on the nature of differential itself. The growth accounting computes the TFP dynamics accurately only under certain conditions based mainly on assumption of sufficiently small changes in variables.
\end{abstract}

Keywords: growth accounting, TFP, approximation problem, Taylor Theorem, Hessian Matrix

JEL Classification: E25, C02

\section{Introduction}

The growth accounting principle presented originally by Solow (1957) is at present widely used by a lot of institutions like IMF, OECD, national banks and ministries. The growth accounting is mainly being used for tracking the growth of the intercept (Solow's residual), usually understood as technological change or total factor productivity - TFP. Growth accounting is a Cobb-Douglas (C-D) production function dynamics with Hicks neutral technological progress in fact. The aggregate production function is expressed as

$$
Y=A K^{\alpha} N^{\beta},
$$

where $A$ stands for the "total factor productivity" (TFP), $K$ for capital stock, $N$ for labour, while $\alpha, \beta$ are elasticities of production on capital and labour respectively. In other words equation (1) says that output depends on capital, labour and on the level of TFP.

* University of Economics, Prague (j_cadil@yahoo.com).

I am grateful to Petr Kadeřábek (Charles University - IES) and Miloš Kaňka (University of Economics,

Prague, Department of Mathematics) for fruitful comments. 
Under Solow's broadly accepted constant returns to scale assumption when the function (1) is homogeneous of degree one (in other words $\alpha+\beta=1$ ) and equation (1) looks like

$$
Y=A K^{\alpha} N^{(1-\alpha)} .
$$

Two important things regarding (1) or (2) respectively still concern most economists and should be pointed out here. First the diminishing returns to capital lead to conclusion that the share of capital on output (capital-output ratio) should be increasing over time. But empirical studies do not support such conclusion. One of the most famous Kaldor's Stylized Facts (cited in Barro, Sala-i-Martin 1995 for example) proves that capital output-ratio is constant over time.

The second problem is related to the level of TFP. There is an ongoing debate concerning the nature and role of TFP in economic growth. Some economists argue that the level constant $A$ in its original form is nothing more than a "measure of our ignorance" (Abramovitz 1956 and 1993, respectively). The higher the $A$ and its growth the worse is the production level and dynamics being explained by the labour and capital variables and we should add some more explanatory variables to reduce this "ignorance". Another problem occurs when we try to explain where $A$ comes from. Sometimes we can come across term "manna from heaven" resulting from no actual cost of the TFP.

These two issues probably led to rise of the endogenous growth theory ${ }^{1}$ that tries to explain non-diminishing returns to capital by $R \& D$, human capital or infrastructure and to explain the output growth in endogenous not exogenously given terms. Nevertheless the main stream represented by important institutions still understands the constant $A$ mainly as a level of technology, at best as a basket for other factors affecting the output besides capital and labour.

To estimate the intercept $A$ and elasticity $\alpha$ in equation (2) two possible procedures are being used. The first one is quite popular for its simplicity and is based on standard factor pricing. According to optimization of subject behaviour the marginal cost of factor should equal marginal revenues of that factor or for labour that is usually used

$$
\beta=(1-\alpha)=\frac{w N}{P Y},
$$

where $w$ is total labour cost and $P Y$ is nominal output. However, this works only under perfect competition on the goods and services market condition. If the imperfect competition on the goods market is taken into account the expression above must be altered as

$$
\beta=\frac{w N}{P\left(1+\frac{1}{e_{p d}}\right) Y},
$$

1 See Barro, Sala-i-Martin (1995) for discussion. 
where $e_{p d}$ stands for price elasticity of demand. The equation (3b) is not as convenient as (3a) and therefore not preferred. $\beta$ is then usually computed for a discrete time as average between two periods ${ }^{2}$.

The second possible approach is of standard econometric nature. Taking logarithms and first differences of (2) with respect to time gets

$$
\Delta \ln Y=\Delta \ln A+\alpha \Delta \ln K+(1-\alpha) \Delta \ln N .
$$

Although the procedures for $A$ and $\alpha$ estimation are quite different it has probably no substantial effect on growth accounting and the TFP growth estimate discussed below. The difference between econometric approach (4) and estimation of elasticity as a share (3a) is usually not very high ${ }^{3}$. Generally it can be stated that the higher is the share of capital in output, the higher is the dynamic contribution of capital growth to the total output growth ${ }^{4}$.

Common approximation leading to standard growth accounting equation is being performed through total differentiation of (2) with respect to time and dividing by $Y$ or out of equation $(4)^{5}$. We get Solow's original equation called usually growth accounting as

$$
\frac{\Delta Y}{Y}=\frac{\Delta A}{A}+\alpha \frac{\Delta K}{K}+(1-\alpha) \frac{\Delta N}{N} .
$$

The growth of output then depends on the growth of TFP, capital and labour. Solving the TFP growth rate out of (5) as residual we get

$$
a=y-\alpha k-(1-\alpha) n,
$$

where $a=\frac{\Delta A}{A}, y=\frac{\Delta Y}{Y}, k=\frac{\Delta K}{K}, n=\frac{\Delta N}{N}$.

Equation (6) computes the TFP dynamics and it is this equation that is still being used for computing the technological growth since 1957 and is popular among lots of economists and institutions.

However, some economists realized quite early that equation (6) yields surprising results regarding the TFP growth and its influence on total output dynamic. It is obvious that for certain periods of time the TFP plays much more important role than was assumed. As Abramovitz (1993) remembers:

"...The result was a calculation that seemed that over some eight decades, the combined per capita input of labor and capital accounted for only 10 percent of the growth of the net output per capita. What we now call total factor productivity (TFP) appeared to be responsible for the remaining 90 percent... This result, at least in the

2 See Hájek (2006) for example.

3 See OECD Economic Working Paper No.248, 2000 for example.

4 See Sources of Economic Growth: An Extensive Growth Accounting Exercise, IMF 2000 for further elasticity measurement and its impact on TFP level and growth discussion.

5

It is usually assumed that $(\ln y)^{\prime}=\frac{y^{\prime}}{y}$ where $y$ stands for a function. 
small share it assigned to capital intensity and in the dominant importance of TFP, was a surprise to me and, it seems, to most economists."

TFP then becomes the most important factor explaining the economic growth and economist start to focus on resolving it. The economic main stream, represented by endogenous growth theory at present time, is in fact trying to reduce the TFP importance by adding other variables counting in favour of capital intensity as mentioned above. It is certainly not intention of this paper to criticize this approach; on the contrary I am convinced that endogenous growth theory is on a good track and that there is much more than just capital and labour what is important for the economic growth.

Nevertheless the TFP importance also varied through time from not being very important in nineteenth century to being most important in twentieth century. Let us cite Abramovitz again:

"Our nineteenth-century growth account as depicted in Table 1 holds another surprise: the sources of growth are quite at variance with the twentieth century results. It finds that the growth of capital intensity was a much larger source of labor productivity growth in the nineteenth century than in the twentieth."

Abramovitz is suggesting a factor bias of technological progress (besides possibility of overall technological acceleration) as a possible explanation of TFP variation through time. According to him the nature of technological change in the nineteenth and twentieth century differed significantly. Abramovitz argues that in the nineteenth century there was a tangible capital-using technological progress promoting high capital per worker accumulation. On the other hand, twentieth century technological progress shifted towards intangible capital like education and training. This shift then exhibited in capital in income share decline and rise of TFP share in per capita growth.

There is probably much truth in Abramovitz's explanation. Nevertheless I believe that one of possible (although not very substantial) reasons for the TFP variation and its share in economic growth lies directly in the growth accounting method and use of total differential for solving the dynamics for certain cases.

\section{Approximation Problem of Growth Accounting}

As said above equation (6) is often used to estimate the growth of TFP in countries by economists and important institutions like the OECD. However, this TFP dynamics approximation is based on total differential which is correct only for small changes in explanatory variables ${ }^{6}$. Even Solow himself mentions this problem in his original paper:

“...The natural thing to do, for small changes, is to approximate the period 2 curve by its tangent at P2 (or the period 1 curve by its tangent at P1). This yields an approximately corrected point $P_{12}$ and an estimate for $\triangle A / A \ldots$..."

This means that if the changes of capital or labour are relatively greater than small, then the differential approximation might cause serious distortion in TFP growth estimate and economic conclusions.

For these cases such weak approximation of TFP dynamic function should be replaced by better or a closer one. The Taylor series is a common mathematical tool used

6 See for example Cullen (1991) pp. 51-53 for Euler's method mathematical discussion. 
for solving differential equations or approximation of continuous function in some interval and is suitable for this purpose ${ }^{7}$.

For the highest possible simplicity the Taylor expansion of second order can be used for approximation of the function of $m$ variables $f\left(x_{1}, \ldots, x_{m}\right)$ and is generally defined as

$$
\begin{aligned}
& f\left(x_{1}+\Delta x_{1}, \ldots, x_{m}+\Delta x_{m}\right)=f\left(x_{1}, \ldots, x_{m}\right)+\Delta x_{1} \frac{\delta f\left(x_{1}, \ldots, x_{m}\right)}{\delta x_{1}}+\ldots+\Delta x_{m} \frac{\delta f\left(x_{1}, \ldots, x_{m}\right)}{\delta x_{m}}+ \\
& +\frac{1}{2 !}\left[\Delta x_{1}^{2} \frac{\delta^{2} f\left(x_{1}, \ldots, x_{m}\right)}{\delta x_{1}^{2}}+2 \Delta x_{1} \Delta x_{2} \frac{\delta^{2} f\left(x_{1}, \ldots, x_{m}\right)}{\delta x_{1} \delta x_{2}}+\ldots+2 \Delta x_{1} \Delta x_{m} \frac{\delta^{2} f\left(x_{1}, \ldots, x_{m}\right)}{\delta x_{1} \delta x_{m}}+\ldots+\right. \\
& \left.+\Delta x_{m}^{2} \frac{\delta^{2} f\left(x_{1}, \ldots, x_{m}\right)}{\delta x_{m}^{2}}\right] .
\end{aligned}
$$

For the purpose of approximating the equation (6) we can rewrite (7) as

$$
\begin{aligned}
& (Y+\Delta Y)=f(A+\Delta A, K+\Delta K, N+\Delta N)=f(A, K, N)+\Delta A \frac{\delta f(A, K, N)}{\delta A}+ \\
& +\Delta K \frac{\delta f(A, K, N)}{\delta K}+\Delta N \frac{\delta f(A, K, N)}{\delta N}+\frac{1}{2 !}\left[\Delta A^{2} \frac{\delta^{2} f(A, K, N)}{\delta^{2} A}+\Delta K^{2} \frac{\delta^{2} f(A, K, N)}{\delta^{2} K}+\right.
\end{aligned}
$$$$
\Delta N^{2} \frac{\delta^{2} f(A, K, N)}{\delta^{2} N}+2 \Delta A \Delta K \frac{\delta^{2} f(A, K, N)}{\delta K \delta A}+2 \Delta A \Delta N \frac{\delta^{2} f(A, K, N)}{\delta A \delta N}+
$$$$
\left.2 \Delta K \Delta N \frac{\delta^{2} f(A, K, N)}{\delta K \delta N}+\Delta N^{2}\right]
$$

And after dividing (8a) by $Y$ for the output dynamics and using the (6) terms we get

$$
\begin{aligned}
& y=a+\alpha k+(1-\alpha) n+\alpha(1-\alpha)(k n)+\alpha(k n)+(1-\alpha)(a n)+\frac{1}{2} \alpha(\alpha-1)(k)^{2}+ \\
& +\frac{1}{2}(1-\alpha)(-\alpha)(n)^{2} .
\end{aligned}
$$

Series (8b) represents output growth approximation according to Taylor series expansion. The next logical step is to compute the growth of TFP out of this series. The TFP dynamics approximation then looks like

$$
a=\frac{y-\alpha k-(1-\alpha) n-\alpha(1-\alpha)(k n)-\frac{1}{2} \alpha(\alpha-1)(k)^{2}-\frac{1}{2}(1-\alpha)(-\alpha)(n)^{2}}{1+\alpha k+(1-\alpha) n)} .
$$

7 See Zakon (2004) or Cullen (1991) for example. 
The difference between (9) and (6) expresses the difference between standard weak TFP dynamics approximation and closer approximation according to addition of Hessian matrix ${ }^{8}$ of second derivatives. Modifying equation (2) by dividing both sides with labour force ${ }^{9}$ and applying similar procedure as (6) to (9) yields results usable for analysing the TFP dynamics on the base of capital per labour unit variable as

$$
D a=\left(\frac{\alpha \bar{k}}{1+\alpha \bar{k}}\right)\left(\bar{y}-\frac{1}{2} \bar{k}(\alpha+1)\right)
$$

It is quite obvious that the higher is the positive difference between output per capita and capital per capita growth (times one half and elasticity plus one) the higher is a positive difference between modified approximation (6) and approximation with Hessian matrix. In other words the more is the TFP overestimated. On the other hand, as capital per labour unit grows rapidly contrary to output growth the output then the TFP growth computed by (6) is underestimated. Figure 1 shows the graphical explanation of (10) with $\alpha$ set arbitrary equal to 0,3 and growth rates are assumed to be positive.

\section{Figure 1}

\section{The TFP Approximation Difference (based on own calculation)}

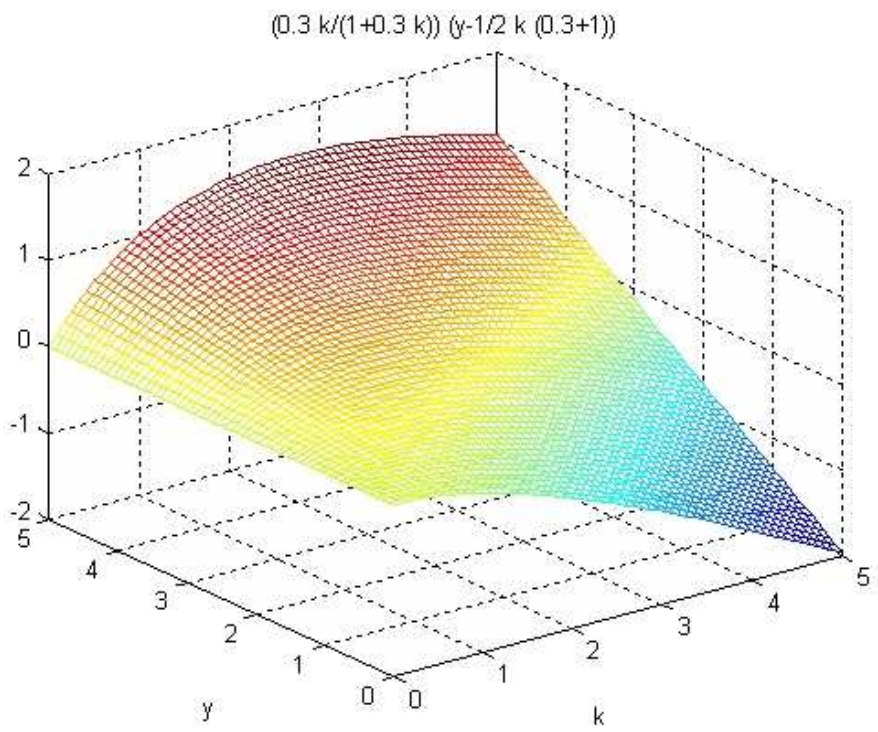

Of course equation (6) might generate correct results (meant as the same as Hessian approximation), however, it holds true only for cases when the difference between (6) and (9) is reaching zero. Using the modified (10) again it is graphically an area in the middle of the plane (except when $k$ is zero).

8 Hessian matrix is the second derivative member in (8a). See Abadir, K.,M., Magnus, J.R. (2005) for example.

9 Common modification often used to avoid multicolinearity in practical applications. Used even by Solow himself (Solow 1957, p. 313). 
The more general case when output and capital growth rates can be also negative (case of deeper recession or crisis) is shown in Figure 2.

\section{Figure 2}

The TFP Approximation Difference (general case, based on own calculation)

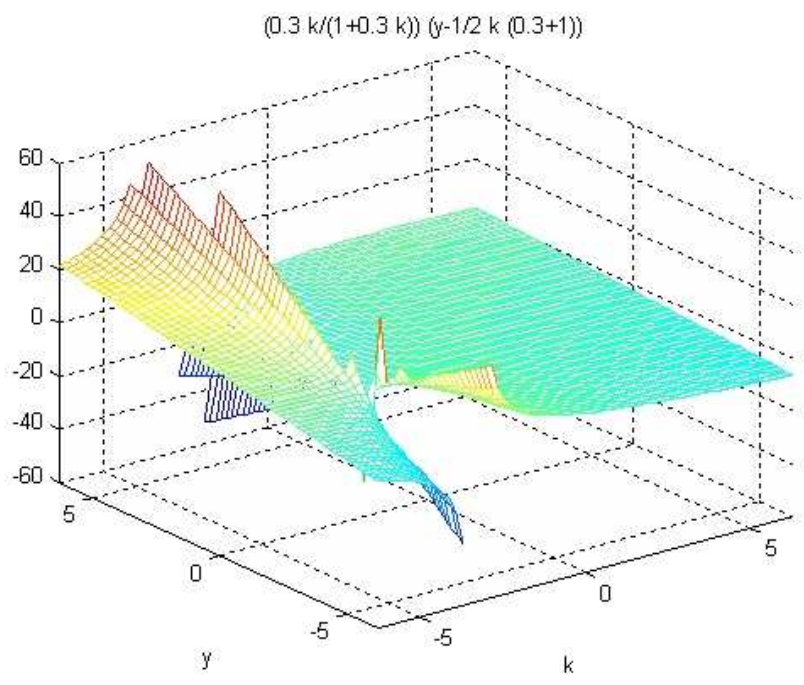

Two extremes and dualities can be found in such unusual case. First, as the output per capita grows and capital per capita decreases something quite weird is happening to the economy and the TFP is growing rapidly. However, the estimation by (6) would overestimate the TFP development or possibly underestimate it depending on actual difference of variables. The similar case happens when capital is growing and output is decreasing.

\section{Examples of TFP Approximation Revision}

First example of TFP approximation using (9) and comparison with (6) and its influence on economic conclusions regarding the TFP dynamics and the overall economic development is taken from Asian Productivity Organization (APO) publication - Total Factor Productivity Growth: Survey Report (Lee, Fu, Thangavelu 2004). Three fast growing Asian economies - Taiwan, Singapore and South Korea - are being analysed for this purpose. Table 1 shows the results. Again $y$ stands for output growth; $k$ is the growth of capital and $n$ is the labour force growth rate. $D a$ reflects the difference between using (9) and (6) for total factor productivity (TFP) approximation.

Although differences in TFP approximation are not very high the TFP approximation using (9) is pointing to slight underestimation of TFP growth mainly in Singapore reaching $0.34 \%$ and overestimation in Taiwan reaching $0.25 \%$. TFP dynamics has then slightly lower contribution to total output growth than estimated by (6) in the case of overestimation and higher in the case of underestimation decreasing the variation between time periods and countries as well. 
Table 1

TFP Approximation and Revision, Example No. 1

Growth rates and contributions (\%)

\begin{tabular}{|c|c|c|c|c|c|c|}
\hline \multicolumn{7}{|c|}{ TAIWAN } \\
\hline period & $y$ & $\alpha(\boldsymbol{k})$ & $(1-\alpha) n$ & TFP & TFP rev & $\mathrm{Da}$ \\
\hline $1965-70$ & 11.060 & 3.680 & 3.680 & 3.700 & 3.447 & 0.253 \\
\hline $1971-80$ & 10.320 & 5.140 & 3.080 & 2.100 & 1.968 & 0.132 \\
\hline $1981-90$ & 8.020 & 4.610 & 1.680 & 1.730 & 1.681 & 0.049 \\
\hline 1991-99 & 6.520 & 3.300 & 1.070 & 2.150 & 2.093 & 0.057 \\
\hline 1965-99 & 8.810 & 4.260 & 2.280 & 2.270 & 2.157 & 0.113 \\
\hline \multicolumn{7}{|c|}{ KOREA } \\
\hline period & $y$ & $\alpha(k)$ & $(1-\alpha) n$ & TFP & TFP rev & $D a$ \\
\hline $1972-75$ & 8.990 & 4.950 & 2.030 & 2.010 & 1.962 & 0.048 \\
\hline $1975-80$ & 7.420 & 6.260 & 1.610 & -0.450 & -0.268 & -0.182 \\
\hline $1980-85$ & 6.620 & 4.650 & 1.030 & 0.940 & 0.992 & -0.052 \\
\hline $1985-90$ & 7.370 & 4.790 & 2.100 & 0.480 & 0.520 & -0.040 \\
\hline $1990-95$ & 8.040 & 4.610 & 1.390 & 2.040 & 2.032 & 0.008 \\
\hline 1995-99 & 5.180 & 3.130 & -0.010 & 2.060 & 2.077 & -0.017 \\
\hline $1972-99$ & 7.880 & 4.740 & 1.220 & 1.920 & 1.915 & 0.005 \\
\hline \multicolumn{7}{|c|}{ SINGAPORE } \\
\hline period & $y$ & $\alpha(\boldsymbol{k})$ & $(1-\alpha) n$ & TFP & TFP rev & $D a$ \\
\hline $1970-75$ & 9.540 & 10.206 & 1.616 & -2.283 & -1.938 & -0.344 \\
\hline 1976-80 & 7.990 & 5.980 & 1.806 & 0.204 & 0.207 & -0.003 \\
\hline 1981-85 & 5.690 & 6.385 & 1.218 & -1.913 & -1.689 & -0.224 \\
\hline $1986-90$ & 8.110 & 3.511 & 1.904 & 2.696 & 2.561 & 0.135 \\
\hline 1991-95 & 7.750 & 4.062 & 0.938 & 2.750 & 2.655 & 0.095 \\
\hline 1996-98 & 5.450 & 5.859 & 1.545 & -1.954 & -1.736 & -0.218 \\
\hline
\end{tabular}

Source: Total Factor Productivity Growth: Survey Report (Asian Productivity Organization, 2004). TFP Revision computed according equation (9).

Another analysis is focused on yearly TFP development in China based on work of Yang Yao (2001). Table 2 shows the results of TFP growth revision.

Table 2

TFP Approximation and Revision, Example No. 2

Growth rates and contributions (\%)

\begin{tabular}{|c|c|c|c|c|c|c|}
\hline year & $\boldsymbol{y}$ & $\alpha(\boldsymbol{k})$ & $(\mathbf{1}-\alpha) \boldsymbol{n}$ & $\boldsymbol{T F P}$ & $\boldsymbol{T F P}$ rev & $\boldsymbol{D a}$ \\
\hline 1953 & 13.170 & 6.564 & 1.015 & 4.548 & 4.534 & 0.014 \\
\hline 1954 & 5.780 & 5.385 & -0.641 & -1.425 & -1.098 & -0.327 \\
\hline 1955 & 6.440 & 4.311 & 0.223 & 0.708 & 0.821 & -0.113 \\
\hline 1956 & 14.110 & 4.962 & 1.270 & 7.468 & 7.200 & 0.268 \\
\hline 1957 & 4.500 & 5.538 & -2.151 & -3.173 & -2.715 & -0.458 \\
\hline 1958 & 22.100 & 7.404 & 3.393 & 8.571 & 7.784 & 0.787 \\
\hline 1959 & 8.060 & 9.234 & -3.663 & -5.171 & -3.984 & -1.187 \\
\hline 1960 & -1.420 & 6.978 & 5.451 & -9.000 & -7.876 & -1.124 \\
\hline
\end{tabular}




\begin{tabular}{|c|c|c|c|c|c|c|}
\hline 1961 & -18.430 & 1.035 & -1.087 & -18.716 & -18.641 & -0.075 \\
\hline 1962 & -6.510 & -0.027 & -0.670 & -5.972 & -6.004 & 0.032 \\
\hline 1963 & 10.700 & 0.765 & 1.311 & 8.822 & 8.660 & 0.162 \\
\hline 1964 & 16.950 & 1.293 & 2.702 & 13.235 & 12.762 & 0.473 \\
\hline 1965 & 16.950 & 2.724 & 2.588 & 11.573 & 11.010 & 0.563 \\
\hline 1966 & 17.020 & 2.451 & 2.610 & 11.972 & 11.417 & 0.555 \\
\hline 1967 & -7.240 & 1.380 & 5.577 & -11.154 & -10.733 & -0.421 \\
\hline 1968 & -6.540 & 0.699 & 5.056 & -9.640 & -9.349 & -0.291 \\
\hline 1969 & 19.360 & 1.260 & 3.037 & 15.433 & 14.850 & 0.583 \\
\hline 1970 & 23.220 & 2.958 & 2.976 & 17.497 & 16.585 & 0.912 \\
\hline 1971 & 9.130 & 2.901 & 1.481 & 3.597 & 3.443 & 0.154 \\
\hline 1972 & 2.850 & 2.493 & -0.962 & -1.218 & -1.133 & -0.085 \\
\hline 1973 & 8.300 & 2.973 & 0.792 & 4.242 & 4.147 & 0.095 \\
\hline 1974 & 1.150 & 2.505 & -5.347 & -2.860 & -2.711 & -0.149 \\
\hline 1975 & 8.320 & 2.544 & 1.130 & 4.215 & 4.088 & 0.127 \\
\hline 1976 & -2.650 & 2.175 & 5.225 & -6.351 & -6.098 & -0.253 \\
\hline 1977 & 7.790 & 2.529 & 0.917 & 4.015 & 3.914 & 0.101 \\
\hline 1978 & 12.270 & 2.955 & 1.215 & 8.013 & 7.750 & 0.263 \\
\hline 1979 & 7.600 & 3.273 & 0.813 & 2.759 & 2.707 & 0.052 \\
\hline 1980 & 7.810 & 2.589 & 1.183 & 3.198 & 3.090 & 0.108 \\
\hline 1981 & 5.260 & 1.698 & 0.769 & 1.196 & 1.155 & 0.041 \\
\hline 1982 & 0.820 & 2.460 & -3.917 & -2.529 & -2.398 & -0.131 \\
\hline 1983 & 19.900 & 2.412 & 3.680 & 13.764 & 12.976 & 0.788 \\
\hline 1984 & 15.180 & 2.727 & 2.163 & 10.199 & 9.750 & 0.449 \\
\hline 1985 & 13.470 & 3.618 & 2.005 & 7.241 & 6.885 & 0.356 \\
\hline 1986 & 8.860 & 3.966 & 0.945 & 2.801 & 2.745 & 0.056 \\
\hline 1987 & 11.570 & 3.120 & 1.718 & 6.210 & 5.946 & 0.264 \\
\hline 1988 & 11.270 & 3.156 & 1.604 & 6.007 & 5.763 & 0.244 \\
\hline 1989 & 4.070 & 2.847 & -0.254 & -0.436 & -0.366 & -0.070 \\
\hline 1990 & 3.830 & 2.691 & -0.215 & -0.380 & -0.318 & -0.062 \\
\hline 1991 & 9.160 & 3.600 & 1.017 & 3.880 & 3.777 & 0.103 \\
\hline 1992 & 14.240 & 4.200 & 1.318 & 8.493 & 8.169 & 0.324 \\
\hline 1993 & 13.500 & 3.852 & 1.369 & 8.038 & 7.732 & 0.306 \\
\hline 1994 & 12.660 & 3.441 & 1.363 & 7.637 & 7.357 & 0.280 \\
\hline 1995 & 10.170 & 3.462 & 1.118 & 5.168 & 5.009 & 0.159 \\
\hline period & $\mathbf{y}$ & $\alpha(k)$ & $(1-\alpha) n$ & TFP & TFP rev & $D a$ \\
\hline $1953-1959$ & 10.590 & 6.201 & 0.608 & 1.638 & 1.773 & -0.135 \\
\hline $1960-1962$ & -8.790 & 2.661 & -0.396 & -11.234 & -10.880 & -0.354 \\
\hline $1963-1978$ & 8.600 & 2.163 & 1.463 & 4.463 & 4.305 & 0.158 \\
\hline $1979-1988$ & 10.170 & 2.901 & 1.563 & 5.078 & 4.875 & 0.203 \\
\hline 1989-1990 & 3.950 & 2.769 & -0.234 & -0.408 & -0.342 & -0.066 \\
\hline 1991-1995 & 12.640 & 3.738 & 1.300 & 7.334 & 7.069 & 0.265 \\
\hline
\end{tabular}

Source: In Search of a Balance: Technological Development in China, Yao Y. 2001. TFP Revision computed according equation (9). 
The TFP difference is again usually quite low in absolute values, however for certain years like 1958-1960 or in 1970 and 1983 the difference between approximations (6) and (9) is substantial. These years were characterized mainly by high difference between capital per capita accumulation and GDP per capita growth. For example in 1959 the capital was growing by $30.78 \%$ and GDP only by 8.06 resulting in significant TFP growth underestimation. On the contrary in 1970 the GDP per capita grew by $23.22 \%$ and capital per head only by $9.86 \%$ resulting in TFP growth overestimation. However, in this case the relative difference is not that high as in 1959 or 1960.

Nevertheless, it is quite clear that for the cases of high differences between variables the standard growth accounting method is bringing slightly, and in extreme cases significantly, biased results as equation (10) predicts. The utilization of standard growth accounting is leading to imperfect approximations and biased conclusions regarding TFP growth in these cases and using (9) seems as a suitable solution.

\section{Conclusion}

The standard growth accounting method used widely for GDP growth decomposition and TFP growth calculation, works well only if the changes of variables are sufficiently small. If the changes of variables are higher, the approximation based on differentials becomes more or less inaccurate depending on differences in variable dynamics. Such weak approximation may lead to TFP distortion and to biased conclusions. Then we face an undervaluation or overvaluation of TFP growth, especially in fast growing countries like China or Singapore.

Some more accurate approximation like adding the Hessian matrix of second derivatives must be performed to get results that are closer to reality. Out of the studies analysed in this paper it can be concluded that the differences in TFP estimated by standard growth accounting method and the Hessian matrix method are visible but from the economic point of view usually insignificant (the difference is often relatively high but in absolute numbers it is quite negligible). However, for certain cases like Chinese economy in 1959 or Singapore in period 1970-75 and 1996-98 the difference becomes quite large and substantial and for these cases the TFP estimates should be revisited and the approximation (9) suggested in this paper could be a suitable tool.

\section{References}

Abadir, K.M., Magnus, J.R. (2005), Matrix Algebra. Cambridge : Cambridge University Press.

Abramovitz, M. (1993), "The Search for the Sources of Growth: Areas of Ignorance, Old and New." The Journal of Economic History, 53 (2), pp. 217-243.

Barro, R. J., Sala-i-Martin, X. (1995), Economic Growth. McGraw-Hill.

Cullen, Ch.G. (1991), Linear Algebra and Differential Equations. PWS-Kent Publishing Company.

Fu,T. (2004), "National Report-China/Taiwan," in Total Factor Productivity Growth: Survey Report. Asian Productivity Organization (APO).

Hájek, M. (2005), "Ekonomický růst a souhrnná produktivita faktorů v České republice v letech 1992-2004." CES WP No. 5.

Lee, B. (2004), “National Report-Republic of Korea,” in Total Factor Productivity Growth: Survey Report. Asian Productivity Organization (APO).

Scarpetta, S., Bassanini, A., Pilat, D., Schreyer, P. (2000), "Economic Growth in the OECD Area: Recent Trends at the Aggregate and Sectoral Level." OECD 2000 WP No. 248. 
Senhadji, A. (2000), "Sources of Economic Growth: An Extensive Growth Accounting Exercise." IMF Staff Papers No. 47/1 2000.

Solow, R., M. (1957), "Technical Change and the Aggregate Production Function." The Review of Economics and Statistics, 39 (3), August, pp. 12-320.

Thangavelu, S.M. (2004), "National Report-Singapore," in Total Factor Productivity Growth: Survey Report. Asian Productivity Organization (APO).

Yao, Y. (2001), "In Search of a Balance: Technological Development in China." China Center for Economic Development 2001 WP No. C2001003.

Zakon, E. (2004), Mathematical Analysis. West Lafayette : Trillia Group. 